\title{
PHOTOCHEMISTRY AND ENZYMOLOGY OF PHOTOSYNTHESIS
}

\section{PROGRESS REPORT}

For Period November 1, 1979 through March 31, 1980

Richard Radmer, John Golbeck and Bruno Velthuys

MARTIN MARIETTA CORPORATION

Martin Marietta Laboratories

1450 South Rolling Road

Baltimore, Maryland 21227

April 1980

Prepared for

The U. S. Department of Energy, Chicago Operations Office

Under Contract

DE-ACO-2-76ER3326 


\section{DISCLAIMER}

This report was prepared as an account of work sponsored by an agency of the United States Government. Neither the United States Government nor any agency Thereof, nor any of their employees, makes any warranty, express or implied, or assumes any legal liability or responsibility for the accuracy, completeness, or usefulness of any information, apparatus, product, or process disclosed, or represents that its use would not infringe privately owned rights. Reference herein to any specific commercial product, process, or service by trade name, trademark, manufacturer, or otherwise does not necessarily constitute or imply its endorsement, recommendation, or favoring by the United States Government or any agency thereof. The views and opinions of authors expressed herein do not necessarily state or reflect those of the United States Government or any agency thereof. 


\section{DISCLAIMER}

Portions of this document may be illegible in electronic image products. Images are produced from the best available original document. 
I. LIGHT HARVESTING AND ELECTRON TRANSPORT IN C 4 PLANTS

During the past year we reported that, in contrast to the findings of Hardt and Kok (Plant Physiol. 62, 59-63, 1978), bundle sheath chloroplasts from corn contain only about $15 \%$ as much photosystem II (PS II) activity as corn mesophyll chloroplasts*. This conclusion was based on measurements of $\mathrm{O}_{2}$ evolution using oxidized phenylenediamine or 2,5-dimethylp-benzoquinone as the terminal electron acceptors, and on the variable fluorescence obtained from room-temperature fluorescence rise curves. Parallel experiments on the same chloroplast preparations using the PS II donor tetraphenylboron -- which is oxidized by photochemically active centers regardless of whether or not the $\mathrm{O}_{2}$-evolving system is intact -- led to an estimate of $\sim 30 \%$ for the bundle sheath/mesophylI PS II ratio." These data suggested that the $\mathrm{O}_{2}$-evolution system may have been damaged during the enzyme-based chloroplast isolation procedure, leading to artifically low bundle sheath mesophyll PS II ratios.

To test this hypothesis, we isolated bundle sheath and mesophyll chloroplasts by the method of Lee (Virginia J. of Sci. $28,157-162,1977)$. This procedure, which is not enzyme based, includes a step in which the leaf segments are vacuum-infiltrated with dithiothreitol and polyethylene glycol before differential grindings**. We were able to obtain bundle-sheath chl

* Progress Report and Renewal Proposal, July 1979; Progress Report, April 1.979 .

** To assure that we duplicated his procedure as closely as possible, we contacted Dr. Lee (now working at Diamond Shamrock Co., Cleveland, Ohio) several times during the course of these experiments. 
$\mathrm{a} / \mathrm{b}$ ratios of 6.5 to 7.0 using this procedure, which indicated that the preparations contained less than $10 \%$ mesophyll contamination.

The bundle sheath/mesophyll ferricyanide Hill activity ratio in these chloroplast preparations was about $20 \%$ in the presence of the uncoupler methylamine. (This ratio increased to $50 \%$ in the absence of uncoupler, reflecting differences in the degree of coupling in the isolated chloroplasts of the two cell types.) When dimethylquinone (a compound which can efficiently accept electrons from PS. II) was used as the Hill acceptor, the bundle sheath/mesophyll ratio was about $30 \%$. Since 1) there seems to be some variability in these preparations (which can be ascribed to differences in, e.g., leaf age), and 2) we have observed that these two acceptors have different light saturation characteristics, the observed differences in the bundle sheath/mesophyll ratio between these two acceptors may not be significant (see below and section IV).

These findings were corroborated by spectral measurements of $\triangle \mathrm{pH}$ using the PS II donor tetraphenylboron. Like the earlier data, these measurements indicated that the bundle sheath/mesophyil. PS II ratio is about $30 \%$.

This latest round of experiments generally corroborates our earlier findings, viz, that bundle sheath chloroplasts are deficient in PS II compared to those of the mesophyll. The non-enzymatic chloroplast preparation procedure may preserve a greater percentage of $\mathrm{O}_{2}$-evolving activity (compared to previously employed enzymatic procedures), but not enough to alter the basic conclusions.

An interesting aspect of the spectral PS II - PS I measurements is that there seems to be less divergence in the PS II/PS I and P700/chl ratios 
in the two chloroplast types in the later non-enzymatic experiments (Table I). Particularly notable is the much decreased enrichment of P700 in the bundile sheath chloroplasts prepared by the non-enzymatic method. Altinough at first sight this might suggest that the non-enzymatic method, at least in our hands, results in a less pure bindle sheath preparation, this is probably not the case, since 1 ) the measured $a / b$ ratios suggest that that there was very little mesophyll contanination (see above), and 2) the mesophyll fraction prepared non-enzymatically also contained less P700 per chlorophyll than that obtained by the enzymatic method.

\section{TABLE I}

PS2/PSI $\quad$ P700/ChI

\begin{tabular}{llll}
\hline Non-enzymatic method, mesophyll & 1.1 & $1 / 360$ \\
" " $"$ bundle sheath & 0.3 & $1 / 260$ \\
Enzymatic method, mesophyll & 1.4 & $1 / 285$ \\
" " bundle sheath & 0.19 & $1 / 130$ \\
\hline
\end{tabular}

It seems probable that the variations in the results of these experiments reflect, at least partly, variations in the corn itself, $i . e$. we are monitoring parameters that are not constant in nature (see section IV). Despite these variations, however, the important aspects of the data are consistent, viz, the PS II content of bundle sheath chloroplasts is smaller than in those of the mesophyll (at least threefold), and the PS I content is somewhat larger. 


\section{MASS SPECTROMETER STUDIES}

In an earlier proposal (BI 78-13R), we described a mass spectrometerinlet system for measuring the amount and isotopic composition of gases evolved and consumed by photosynthetic tissue in response to single short saturating light flashes. Recently we completed a series of studies in which we used this technique to study photosynthetic $\mathrm{O}_{2}$. evolution with ${ }^{18} 0$-labeled substrates. A paper describing this work recently appeared in FEBS Letters (110, $57-61,1980)$. We reported the following:

1) When $\mathrm{CO}_{2}$-depleted chloroplasts were reactivated with ${ }^{18} 0$-iabeled bicarbonate, all the $\mathrm{O}_{2}$ evolved had the isotopic composition of the $\mathrm{H}_{2} \mathrm{O}$ rather than the $\mathrm{CO}_{2}$. These results support the idea that neither bicarbonate nor $\mathrm{CO}_{2}$ is the immediate source of photosynthetically evolved $\mathrm{O}_{2}$.

2) When these chloroplasts or normal non-depleted chloroplasts were flashed in the presence of $\mathrm{H}_{2}{ }^{18} \mathrm{O}$ added in total darkness, all of the $\mathrm{O}_{2}$, including that evolved in the first few flashes, had the isotopic composition of the added $\mathrm{H}_{2} \mathrm{O}$. This indicates that the $\mathrm{S}_{1}$ state does not contain a bound intermediate oxidation product of $\mathrm{H}_{2} \mathrm{n}$.

3) Although $\mathrm{CO}_{2}$ depletion did not affect the $\mathrm{O}_{2}$ evolution system directly, it drastically decreased the magnitude of the ferricyanideinduced "anomalous double hit," probably due to an inhibition of reactions on the acceptor side of system II. This inhibition may provide a mechanism for regulating cyclic electron flow in vivo.

We were recently requested to prepare a sumary of our work on lightöriven $\mathrm{O}_{2}$ uptake for Fublication in "ihat's Niw in Plault Physiology." A 
copy of this manuscript, entitled 'Uptake of Oxygen by Light-Generated Reductant," is enclosed (Appendix A).

\section{BIOCHEMICAL STUDIES}

\section{Chloroplast Copper Proteins}

1. Action of Salicylaldoxime on Electron Transport Reactions, Fluorescence Yield, and Light-Induced Field Changes in Spinach Chloroplasts

In this study, we were interested in determining the mechanism of inhibition by the copper chelator, salicylaldoxime, of photosynthetic electron transport reactions. This work grew out of an. effort to account for the "missing" copper protein(s) associated with the chloroplast membrane. Since 1) salicylaldoxime inhibits electron flow at or near a site in PS II, 2) earlier chelator studies implied the existence of a metalloprotein (other than manganese) on the water-to-silicomolybdate pathway, and 3) a copper-manganese pigment protein complex implicated in the water-splitting mechanism was isolated from Phacodactylom tricornutrum, it was reasonable to surmise that salicylaldoxime inhibits a copper protein at this site.

In light of these considerations, we reinvestigated the action of salicylaldoxime on photosystem II reactions. We found that its effects involved 1) an irreversible loss of manganese from the water-splitting mechanism, and 2) a reversible effect, which we ascribed to suppression of charge separation within the photosystem II 
trap. We found, however, no evidence to suggest that either mode of inhibition was due to interaction with a copper-containing protein in photosystem II.

A paper describing these findings has been accepted for publication in Arch. Biochem. Biophys; a copy of the manuscript is enclosed with this report (Appendix B). Its abstract reads as follows:

Salicylaldoxime (1-10 mM) inhibits chloroplast electron transport reactions by a reversible and an irreversible modification of photosystem II. The irreversible inhibition correlates with removal of the loosely bound pool of manganese associated with the water-splitting mechanism. The reversible inhibition is characterized by 1) a suppression of artificial donor reactions, 2) a high initial fluorescence yield, and 3) a decline in the amplitude of the flash-induced electric field across the membrane. After removal of the inhibitor, the initial fluorescence yield declines to near-control levels, but the variable portion of the fluorescence rise remains missing. Addition of an artificial donor restores the variable fluorescence yield and normal electron transport rates to 2,6-dichlorophenolindophenol. Characteristics of the reversible inhibition suggest that salicylaldoxime causes suppression of photochemical charge separation in photosystem II.

2. Spinach Thylakoid Polyphenol Oxidase

We recently succeeded in isolating two distinct enzymes containing polyphenol oxidase artivity (PPO I and PPO II) from the thylakoid membranes of spinach chloroplasts. The method of release consists of sonicating osmotically shocked spinach chloroplast membranes in a low ionic-strength medium. Upon liberation, nearly $60 \%$ of the enzyme remains latent, and shows no dopa-mediated oxygeri uptake unless the enzyme 
is activated. We found that the activation process can be accom- plished by incubating the enzyme with Iinolenic acid or any other $\mathrm{C}_{18}$ $\mathrm{C}_{20}$ saturated or unsaturated fatty acid, as well as with trypsin. To our knowledge, linolenic acid represents the first physiologically. important molecule to be positively identified as an activator of plant polyphenol oxidase.

Polyphenol oxidase I has been purified to homogeniety by anmonium sulfate precipitation and Sephadex S-200, DEAE Bio-Gel A, and hydroxylapatite chromatography. The native enzyme has an estimated molecular weight of 158,000 daltons by gel filtration on Sephacryl S200 and S300 but appears to aggregate in a low-salt medium. [This aggregation accounts for the higher molecular weight ( $\sim 260,000$ daltons) stated in the 30 July 1979 report/proposal]. By SDS polyacrylamide gel electrophoresis, the protein appears to have a molecular weight of 42,500 daltons. From these data, we tentatively conclude that the native enzyme is a tetramer of the 42,500 -dalton peptide.

In terms of activity, purified PPO I is an o-diphenol oxidase, showing no detectable levels of ascorbic acid oxidase or monophenol oxidase activities. The $\mathrm{K}_{\mathrm{m}}$ for DL-dopa and oxygen is $8.5 \mathrm{mM}$ and $0.055 \mathrm{mM}$, respectively. The apparent $\mathrm{Km}$ data for other possibly physiological substrates are: $11.6 \mathrm{mM}$ for chlorogenic acid, $15.7 \mathrm{mM}$ for pyrogallo1, $3.13 \mathrm{mM}$ for catechol, $40.7 \mathrm{mM}$ for tryamine, and $0.74 \mathrm{mM}$ for dopamine. The last three substrates show considerable substrate inhibition at concentrations near tineir $\mathrm{K}_{\mathrm{m}}$. Consistent with the 
assignment as a copper-containing protein, the activity is inhibited with the copper chelators cupferron," salicylaldoxime, and diethyldithiocarbamate. With $12.5 \mathrm{mM}$ dopa as substrate, the enzymatic activity is inhibited $50 \%$ by $17.5 \mu \mathrm{M}$ salicylhydroxamic acid. This latter finding is particularly interesting since substituted hydroxamic acids are potent inhibitors of cyanide-insensitive respiration.

Polyphenol oxidase II has an estimated molecular weight of 42,500 daltons by gel filtration on Sephadex G-100. The enzyme has not yet been purified to homogeneity nor have its properties been extensively studied. We are currently operating under the assumption that PPO II represents the monomer form of PPO I; however, we have no data as yet to prove this point. (The aggregation of the protein under low salt conditions may account for the molecular weight of 140,000 daltons reported in the 30 July 1979 report/proposal. All chromatography is now performed in buffer containing $0.2 \mathrm{M}, \mathrm{KCl}$ to avoid this difficulty.)

We found an enormous seasonal variation in the polyphenol oxidase content of spinach chloroplasts $(17.7 \mathrm{mg}$ enzyme/ $\mathrm{kg}$ spinach leaves in August vs $1.6 \mathrm{mg} / \mathrm{kg}$ in mid-December). This would argue against its role as an electron-trasnport intermediate in photosynthesis. A manuscript describing these findings is in preparation. 


\section{OTHER ACTIVITIES}

A review. paper from our laboratory entitled Mechanisms of Electron Flow in Photosystem II and Toward Photosystem I" will appear in Vo1. 31 of Ann. Rev. Plant Physiol. (Appendix C). This review expresses our views on electron transport in green plants, including corn, as developed over the past few years. One of the paper's major objectives was to argue that the popular concept of linear chains consisting of one PS II and one PS I should be abandoned in favor of a looser, nonstoichiometric organization of electron transfer components. According to this view, there are three major (complex) units of electron transfer activity, which are connected by pools of plastoquinone, plastocyanin, and ferredoxin, so called "distributive mediators." The three compelxes are the two photosystems, PS I and PS II and a cytochrome $\underline{b}_{6}-\underline{f}$ complex, similar in structure and function to the ubiquinone-cytochrome $\underline{b}-\underline{c}$ oxidoreductase of mitochondria and bacteria. This cytochrome complex catalyzes electron flow between plastoquinone and plastocyanin, coupled to transmembrane proton translocation, and may also catalyze electron flow between ferredoxin and plastoquinone. Two aspects of this scheme are of particular relevance to our studies of corn: 1) it rationalizes the variability of the relative PS I/ PS II content of chloroplasts, which is so specially striking with corn, and 2) it suggests a mechanism for cyclic electron flow (with ferredoxin replacing PS II as the reductant of plastoquinone).

The characteristics of electron and proton transfer by the cytochromes $\underline{b}_{6}-\underline{f}$ complex have been described in earlier papers from this laboratory. A 
recent paper (Appendix D) further demonstiates the involvement of the cytochrome complex in electron flow between PS II and PS I. The most notable result described in this paper concerns the secondary phase of the electrical field generation, characteristic for electron flow through the cytochrome complex. With thoroughly dark-adapted ch-loroplasts illuminated with flashes, the amplitude of this secondary phase was found to oscillate with flash number in phase with an oscillation of intersystem electron flow. This result is predicted by our earlier proposed scheme, and is not consistent with schemes that consider the cytochrome complex to be involved strictly in cyclic flow. 